\title{
Redução parcial dos teores de gordura e sal em embutido cárneo suíno com utilização de goma carragena e cloreto de potássio
}

\section{Partial reduction of fat and salt contents in fresh pork sausage by using carrageenan and potassium chloride}

\author{
Flávia de Oliveira Paulino, ${ }^{*}$ Teófilo José Pimentel da Silva, ${ }^{* *}$ Robson Maia Franco, ${ }^{* *}$ Mônica Queiroz de Freitas, ${ }^{* *}$ \\ Maria Leonor Fernandes ${ }^{* *}$
}

\begin{abstract}
Resumo
Com o propósito de fornecer um produto cárneo light, principalmente para pacientes obesos e diabéticos, objetivou-se desenvolver um embutido cárneo light, com redução parcial de gordura e sal, substituindo-os por carragena e sal light. Para isso, foram desenvolvidas quatro formulações-teste (F1, F2, F3 e F4) e uma formulação Controle (C). As formulações-teste sofreram redução de 25 e $50 \%$ de gordura e sal. As amostras foram estocadas à temperatura de $4^{\circ} \mathrm{C} \pm 0,5^{\circ} \mathrm{C}$ durante 35 dias. Realizou-se análises de $\mathrm{pH}$, Atividade de água (Aw), composição centesimal, valor calórico, número de ácido tiobarbitúrico (TBA), contagem de microrganismos psicrotróficos, análise sensorial e custo mínimo de produção. As formulações apresentaram resultados bastante satisfatórios, principalmente nas análises de valor calórico, sensorial e custo de produção. Os resultados encontrados neste trabalho justificam a produção de um embutido cárneo light, com utilização de goma carragena e cloreto de potássio $(\mathrm{KCl})$, como substitutos parciais de gordura e sal, respectivamente.
\end{abstract}

Palavras-chave: lingüiça, redução de gordura, redução de sal.

\begin{abstract}
This work aimed at the development of a light fresh pork sausage, intended for consumption mostly by obese and diabetic patients. In this, pork fat and sodium chloride were partially replaced by carrageenan and potassium chloride. Four experimental formulas, with reductions of $25 \%$ or $50 \%$ in fat and sodium chloride and replaced by carragenan and potassium chloride, were evaluated in comparison to a control (without reduction). All samples were stored at $4^{\circ} \mathrm{C} \pm 0,5^{\circ} \mathrm{C}$ for 35 days. The following analyses were carried out in these samples: $\mathrm{pH}$, water activity, chemical composition, caloric value, TBA number, psychrotrophic enumeration, sensory evaluation and minimum production cost. All experimental formulations presented rather satisfactory results, mostly for caloric value, sensory and production cost indices. This evidenced the feasibility of the production of a light meat product by partially substituting fat and sodium chloride by carragenan and potassium chloride, respectively.
\end{abstract}

Keywords: sausage, fat reduction, salt reduction.

\section{Introdução}

Atualmente, produtos considerados saudáveis estão recebendo cada vez mais atenção dos consumidores, sendo que a indústria tem-se antecipado aos desejos desses consumidores e lançado produtos com baixo teor de gordura e cloreto de sódio. Os consumidores almejam por produtos e serviços que os façam se sentirem bem fisicamente, mentalmente e socialmente (Murphy et al., 2004). De acordo com Zanardi et al. (2002), os consumidores modernos estão interessados em produtos gostosos e convenientes, mas também estão preocupados com o valor nutritivo, a segurança e os benefícios que o alimento possa trazer.
Informações sobre produtos com baixo teor de gordura têm repercutido de forma positiva e por isso têm sido objeto de vários estudos. Taxas de aceitação e satisfação de produtos low fat aumentam quando adicionadas da informação low salt (Abiola e Adegbaju, 2001). Os substitutos de gordura são ingredientes que contribuem com um mínimo de calorias e, por isso, não devem alterar sensivelmente o flavor, a suculência, textura, viscosidade e outras propriedades sensoriais (keeton, 1991). Por outro lado, o sal exerce extrema importância na indústria de processamento e, conseqüentemente, no preparo de produtos cárneos. Apesar da importância e da necessidade do sal na elaboração de produtos cárneos, diversos estudos têm mostrado que a

* Programa de Pós-Graduação em Medicina Veterinária (Mestrado) - Higiene Veterinária e Processamento Tecnológico dos Produtos de Origem Animal - Faculdade de Veterinária - Universidade Federal. E-mail: flavia_paulino@bol.com.br.

** Departamento de tecnologia de Alimentos - Faculdade de Veterinária - Universidade Federal Fluminense - Rua Vital Brazil Filho, 64, CEP 24230-340 - mtatjps@vm.uff.br.

*** Programa de Pós-Graduação em Medicina Veterinária (Doutorado) - Higiene Veterinária e Processamento Tecnológico dos Produtos de Origem Animal - Faculdade de Veterinária - Universidade Federal Fluminense - Rua Vital Brazil Filho, 64, CEP $24230-340$.

Autor para correspondência: Teófilo José Pimentel da Silva. E-mail: mtatjpf@vm.uff.br. 
causa principal do aparecimento de problemas de hipertensão deve-se à ação combinada de um fator genético e um conjunto de fatores ambientais. Um dos fatores mais importantes é o excesso de sódio nas dietas (Ruusunen et al., 2003).

O objetivo deste trabalho foi elaborar um embutido cárneo curado, à base de carne suína, lingüiça tipo Toscana, com valor calórico reduzido, de forma a se enquadrar na categoria light. Objetivou-se ainda estudar a redução de 25 e $50 \%$ de gordura por goma carragena, a fim de se reduzir o nível calórico do embutido; avaliar a substituição parcial de sal comum $(\mathrm{NaCl})$ pelo cloreto de potássio ( $\mathrm{KCl}$ ), em 25 e 50\%, com propósito de redução dos níveis de sódio; e aferir características físico-químicas, microbiológicas e sensoriais desses embutidos cárneos.

\section{Material e métodos}

O experimento baseou-se em quatro formulações teste e uma formulação controle de lingüiça suína tipo Toscana. As formulações foram calculadas de forma a reduzir o nível de sódio e gordura. Na Tabela 1 observa-se as reduções e substituições ocorridas nas formulações.

Tabela 1: Reduções e substituições realizadas nas diversas formulações de lingüiça suína tipo Toscana

\begin{tabular}{ccccc}
\hline Formulação & $\begin{array}{c}\text { Redução } \\
\text { de Gordura }\end{array}$ & $\begin{array}{c}\text { Adição de } \\
\text { carragena }\end{array}$ & $\begin{array}{c}\text { Redução } \\
\text { de NaCl }\end{array}$ & $\begin{array}{c}\text { Adição de } \\
\text { KCl }\end{array}$ \\
\hline Controle & $0 \%$ & - & $0 \%$ & - \\
F1 & $50 \%$ & $0,6 \%$ & $50 \%$ & $50 \%$ \\
F2 & $25 \%$ & $0,3 \%$ & $50 \%$ & $50 \%$ \\
F3 & $50 \%$ & $0,6 \%$ & $25 \%$ & $25 \%$ \\
F4 & $25 \%$ & $0,3 \%$ & $25 \%$ & $25 \%$ \\
\hline
\end{tabular}

A gordura foi substituída por um espessante amplamente utilizado na indústria cárnea que é a goma carragena (INS 407) e o sal comum foi substituído por sal light. A matériaprima utilizada foi o recorte magro suíno. As formulações das lingüiças foram realizadas no próprio Laboratório de Tecnologia de Carnes da Faculdade de Veterinária da Universidade Federal Fluminense (UFF).

As análises físico-químicas ocorreram no Laboratório de Controle Químico do Departamento de Tecnologia de Alimentos da Faculdade de Veterinária da UFF e foram realizadas em triplicata. Realizou-se análise de umidade, proteína, cinzas e pH segundo recomendações do Laboratório Nacional de Referência Animal - LANARA - (Brasil, 1981). Na determinação da composição centesimal, a fração de carboidratos foi representada pela fração Nifext, conforme Pedrosa e Cozzolino (2001). A determinação de atividade de água foi realizada em aparelho da marca Decagon. O cálculo do valor calórico dos produtos foi obtido multiplicando-se o teor de lipídeos por $9,1 \mathrm{Kcal} / \mathrm{g}$ e o teor de proteínas e carboidratos por $4,1 \mathrm{Kcal} / \mathrm{g}$ (KEETON, 1991). O número de ácido tiobarbitúrico (TBA) foi determinado através de metodologia recomendada por Tarladgis et al. (1960). As análises de sódio, potássio e cloretos foram realizadas na Faculdade de Farmácia da UFF. Realizou-se análise de umidade do sal através de metodologia recomendada por Brasil (1999).
As análises microbiológicas foram efetuadas no Laboratório de Controle Microbiológico da Faculdade de Veterinária da UFF. A análise microbiológica utilizada neste experimento foi a contagem total de bactérias heterotróficas aeróbias psicrotróficas, realziada em meio PCA ("Plate Count Agar"), segundo técnica descrita por Swanson, Petran e Hanlin (2001). Nesta metodologia as placas permaneceram incubadas a uma temperatura média de $4^{\circ} \mathrm{C} \pm 1^{\circ} \mathrm{C}$ e a leitura procedeu-se a cada sete dias, durante 28 dias.

As lingüiças foram avaliadas sensorialmente no Laboratório de Análise Sensorial da Faculdade de Veterinária da UFF. O teste utilizado foi o de preferência global, segundo Stone e Sidel (1993). Foram selecionados 120 provadores, nãotreinados, aleatoriamente, que realizaram análises nos dias $1,10,20$ e 30 . Os resultados das 120 amostras foram convertidos numa escala de um a cinco, onde cinco era a amostra mais preferida e um era a amostra menos preferida.

Os dados das análises físico-químicas, microbiológica e sensorial foram avaliados através de análise de variância (ANOVA), sendo seguido do teste de Tukey, ao nível de 5\% de significância (SAS, 1999).

\section{Resultados e discussão}

$\mathrm{Na}$ análise de $\mathrm{pH}$ foram avaliados a influência da estocagem e das formulações sobre este parâmetro. Os valores médios de $\mathrm{pH}$ obtidos foram: $5.99,5.68,5.69,5.54$ e 5.51 para as formulações Controle, F1, F2, F3 e F4, respectivamente. A produção de ácido láctico justifica o declínio do $\mathrm{pH}$ até o último dia de análise. Em estudo com lingüiças frescais, Papadima e Bloukas (1999) encontraram pH inicial de 6.24 a 6.48. No $14^{\circ}$ dia os valores de $\mathrm{pH}$ se encontraram próximos a 5.2. Esses dados se aproximam dos encontrados neste trabalho.

Quanto à atividade de água, os valores mostraram diferença entre si $(\mathrm{p}<0,05)$. À medida que os dias passavam, a Aw do produto diminuía. No $1^{\circ}$ dia de análise, o valor médio encontrado foi de 0,93 . Este valor é considerado alto e provavelmente ocorreu em função da ação da goma carragena. Com o passar dos dias, a Aw foi reduzida para 0,90 (14ㅇa) e 0,89 (28 dia). No experimento de Candongan e Kolsarici (2003), a Aw variou de 0,97 a 0,99 em esses autores atribuíram tais valores em função da goma carragena e da pectina utilizada. Papadima e Bloukas (1999) relataram valores de Aw que se iniciou com 0,95 e no 14ํaingiu 0,94 na formulação com $30 \%$ de gordura. Estes valores se aproximam dos encontrados neste trabalho.

Os valores médios da composição centesimal das amostras analisadas podem ser visualizados na Tabela 2 . Todas as amostras, de uma forma geral, contribuíram para o aumento da umidade. A amostra F3 foi a que mais se destacou, com aumento de $15,03 \%$ em relação à formulação Controle. Mesmo a formulação que menos contribuiu (F1) conseguiu aumentar a umidade em até $11,00 \%$. Do ponto de vista industrial, esta é uma característica extremamente desejável. Valores de umidade próximos a $60 \%$ foram relatados por Hsu e Chung (2000). Este valor se aproxima do encontrado neste estudo, confirmando a ação da carragena em agregar água aos embutidos cárneos. 
Tabela 2: Valores médios (\%) da composição centesimal das cinco formulações de lingüiça suína tipo Toscana

\begin{tabular}{ccccccc}
\hline Formulação & Umidade & Proteína & Gordura & Cinzas & Nifext & Total \\
\hline C & $52,65^{\mathrm{a}}$ & $16,11^{\mathrm{a}}$ & $28,43^{\mathrm{a}}$ & $3,64^{\mathrm{a}}$ & $0,00^{\mathrm{a}}$ & 100,82 \\
F1 & $58,44^{\mathrm{b}}$ & $19,66^{\mathrm{b}}$ & $18,09^{\mathrm{b}}$ & $4,11^{\mathrm{b}}$ & $0,00^{\mathrm{a}}$ & 100,30 \\
F2 & $59,67^{\mathrm{c}}$ & $17,72^{\mathrm{c}}$ & $18,04^{\mathrm{b}}$ & $4,88^{\mathrm{b}}$ & $0,00^{\mathrm{a}}$ & 100,32 \\
F3 & $60,58^{\mathrm{c}}$ & $17,50^{\mathrm{c}}$ & $17,15^{\mathrm{c}}$ & $4,38^{\mathrm{b}}$ & $0,39^{\mathrm{a}}$ & 100,00 \\
F4 & $59,10^{\mathrm{c}}$ & $17,28^{\mathrm{c}}$ & $19,08^{\mathrm{d}}$ & $4,60^{\mathrm{b}}$ & $0,00^{\mathrm{a}}$ & 100,06 \\
Média & 58,09 & 17,65 & 20,16 & $4,32^{\mathrm{b}}$ & 0,08 & \\
\hline
\end{tabular}

* Médias seguidas de letras diferentes diferem entre si no teste de Tukey $(p<0,05)$.

** Médias seguidas de pelo menos uma letra igual não diferem entre si no teste de Tukey $(p>0,05)$.

Os teores médios de proteína apresentaram-se em torno de $17,65 \%$. Este valor foi considerado normal e não mostrou muita diferença para a formulação controle. Na formulação controle de Abiola e Adegbaju (2001) o valor médio proteína foi de $27,01 \%$. Este valor é extremamente maior que o encontrado na formulação controle desse trabalho, havendo uma diferença de 10,90\%. Este valor pode ter ocorrido em função de uma maior quantidade de carne suína utilizada na formulação por aqueles autores.

A análise de gordura revelou que todas as amostras contribuíram de forma significativa para a redução desse componente no embutido cárneo. As reduções de gordura contribuíram de forma direta e decisiva para que os embutidos se enquadrassem na classificação light da legislação brasileira. Zanardi et al. (2002) encontraram valores de 22,26\% de gordura em experimento semelhante. Estes valores se encontraram distantes dos encontrados neste trabalho, com diferença mínima de $10 \%$ do teor de gordura. Abiola e Adegbaju (2002) relataram valores $28,69 \%$ de gordura para a formulação controle. Este valor é $0,26 \%$ maior que o encontrado neste experimento e não é considerado significativo.

Todas as formulações apresentaram um ligeiro aumento no teor de cinzas. As amostras F2 (4,88\%) e F4 (4,60\%) foram as que apresentaram maiores teores, enquanto as amostras F3 $(4,38 \%)$ e $\mathrm{F} 1(4,11 \%)$ apresentaram os menores valores de resíduo mineral fixo. O teor médio de carboidrato foi de $0,08 \%$ e não influenciou de forma significativa a composição centesimal.

Quanto ao valor calórico, a formulação Controle apresentou $320,27 \mathrm{cal} / 100 \mathrm{~g}$. As demais formulações apresentaram valor calórico reduzido quando comparadas à formulação Controle. As formulações $\mathrm{F} 3$ e F2 foram as que obtiveram maior redução calórica, com redução de $29,46 \%$ e $27,17 \%$, respectivamente. As formulações $\mathrm{F} 4$ e $\mathrm{F} 1$ obtiveram redução calórica de $24,79 \%$ e $24,71 \%$, respectivamente. Logo, por estes resultados, as formulações que se enquadrariam na classificação de light pela legislação brasileira seriam apenas as formulações F3 e F2.

$\mathrm{Na}$ análise de ácido tiobarbitúrico (TBA) observou-se que no 10 dia de análise o valor encontrado foi de 0,5476 $\mathrm{n}^{\circ}$ moles TBA $/ \mathrm{Kg}$ produto. Para alguns autores, este valor ainda é considerado baixo e indica fase inicial da rancificação em produtos cárneos. No entanto, apesar de haver início de rancificação, este valor não é perceptível na análise sensorial. A partir do $14^{\circ}$ dia o valor médio encontrado foi de $0,5937 \mathrm{n}^{\circ}$ moles TBA $/ \mathrm{Kg}$ produto. Este valor já demonstra um avanço no baixo nível de oxidação.

processo de rancificação oxidativa do produto. O alto valor encontrado no $28^{\circ}$ dia é um fator indesejável, uma vez que pode influenciar negativamente o sabor do produto na análise sensorial. Candongan e Kolsarici (2003) encontraram valores iniciais de $0,433 \mathrm{n}^{\circ}$ moles TBA/Kg carne para a formulação controle. Nas formulações com redução de gordura o TBA apresentou-se entre 0,276 e 0,313 $n^{\circ}$ moles TBA $/ \mathrm{Kg}$ produto. Zanardi et al. (2002) encontraram valores de $0,490 \mathrm{n}^{\circ}$ moles TBA $/ \mathrm{Kg}$ produto aos 28 dias de análise. Segundo os autores, este valor é considerado baixo e indica

$\mathrm{Na}$ análise de umidade, o sal light apresentou teor de 8,35\%. A análise de sódio apresentou teor de 16,31\%, equivalente a $41,48 \%$ de $\mathrm{NaCl}$ no sal. Este valor discorda do indicado na embalagem do produto light, o qual informa teor de $50 \%$ de $\mathrm{NaCl}$. A análise revelou ainda $24,30 \%$ de potássio, o equivalente a $46,42 \%$ de $\mathrm{KCl}$ no sal. O teor de cloreto encontrado foi de $48,80 \%$.

Em experimento de Hsu e Chug (2000) verificou-se que a adição de sal em níveis de 1 a $3 \%$ apresentou efeito positivo no cozimento, conteúdo de gordura e coesão. A adição de sal e carragena em níveis de $2,7 \%$ e $2,0 \%$, respectivamente, geraram produtos com maior grau de aceitação. Estes resultados são diferentes daqueles apresentados neste trabalho. Teores de 2,7\% de sal conferem sabor muito salgado ao embutido frescal suíno, sendo por isso descartados nesse experimento. A adição de $2,0 \%$ de carragena certamente leva a benefícios sensoriais, porém, é condenada do ponto de vista econômico, pois o custo de produção tornaria este produto inviável industrialmente.

A contagem bacteriana, de uma forma geral, foi considerada alta quando comparada aos demais autores. Este fato pode ser explicado pelo fato da goma carragena ser um espessante que agrega água ao alimento e desta forma, aumenta-se a Aw para o crescimento bacteriano. Em relação à análise microbiológica, Bradford et al. (1993) afirmam que a contagem de psicrotróficos é um dos critérios mais importantes para a deterioração em temperaturas de refrigeração. No experimento de Papadima e Bloukas (1999), conseguiram ao $21^{\circ}$ dia de estocagem contagem de psicrotróficos média de $10^{2}$ a $10^{3} \mathrm{UFC} / \mathrm{g}$. Esses valores foram menores que os encontrados neste trabalho, o que pode ser explicado pelo fato do substituto utilizado por esses autores ter sido a gordura vegetal. Em estudo de Murphy et al. (2004), a contagem inicial de microrganismos psicrotróficos manteve-se em $10^{4} \mathrm{UFC} / \mathrm{g}$ e ao final de 12 dias esse número se elevou para $10^{8} \mathrm{UFC} / \mathrm{g}$. Estes valores foram menores aos encontrados neste estudo, provavelmente em função da goma carragena. Com sua habilidade em agregar água, aumenta-se a Aw e conseqüentemente a água disponível para o crescimento bacteriano.

Os resultados da análise sensorial mostraram que no 1임 a amostra que obteve menos aceitação foi a Controle. Isso ocorreu em função desta formulação ser mais gorda que as demais e, por isso, os pedaços de gordura se mostravam mais visíveis. Tal aparência foi condenada pela grande maioria dos provadores, que associaram esta amostra a um fator prejudicial à saúde devido à obesidade e aumento do 
colesterol sanguíneo. Ainda no 1o dia de análise sensorial verificou-se que a amostra F1 obteve aceitação intermediária. As amostras F2, F3 e F4 obtiveram a maior aceitação. Os julgadores afirmaram que a amostra F1 apresentou coloração insatisfatória, embora tenha apresentado boa aparência geral. Tal fato pode ser explicado pela redução de $50 \%$ de sal associado à redução de $50 \%$ de gordura. Essa associação pode ter prejudicado a cura pelo teor de água mais alto, maior adição de carragena e baixo nível de sódio. Nos demais dias de análise (dias 10, 20 e 30) não houve diferença significativa entre as amostras.

Braford et al. (1993), ao estudarem a substituição de gordura por água e carragena, relataram que na análise sensorial as amostras com baixo teor de gordura obtiveram aceitação

\section{Referências}

ABIOLA, S.S.; ADEGBAJU, S.W. Effect of substituting pork backfat with rindo $n$ quality characteristics of pork sausage. Meat Science, v. 58, p. 409-412, 2001.

BERRY, B.W.; BIGNER, M.E. Use of carrageenan and konjac flour gel in low-fat restructured pork nuggets. Food Research International, v. 29, n. 3/4, p. 355-362. 1996.

BRAFORD, D.D. et al. Potassium lactate effects on low-fat fresh pork sausage chubs during simulated retail distribution. Journal of Food Science, v. 58, n. 6, p. 1245-1248, 1993.

BRASIL. Ministério da Agricultura. Secretaria de Defesa Agropecuária. Departamento de Defesa Animal. Coordenação de Laboratório Animal. Métodos analíticos oficiais físico-químicos para controle de carnes, produtos cárneos e seus ingredientes - sal e salmoura. Instrução Normativa oo 20 de 21 de julho de 1999. Diário Oficial da União, Brasília, 9 de Setembro de 1999.

CANDONGAN, K.; KOLSARICI, N. The effects of carrageenan and pectin on some quality characteristics of low-fat beef frankfurters. Meat Science, v. 64, p. 199-206. 2003.

HSU, S.Y.; CHUNG, H.Y. Interactions of konjac, agar, curdlan gum, $k$ carrageenan and reheating treatment in emulsified meatballs. Journal of Food Engineering, v. 44, p. 199-204, 2000. normal. Não houve efeito negativo quanto à adição de carragena. No estudo de Berry e Bigner (1996), o uso da carragena (entre 0,25 e 6\%) em carne reestruturada suína não alterou a maciez, suculência e o processo de cozimento, quando comparado à formulação controle.

\section{Conclusão}

Os dados obtidos neste experimento permitem-nos concluir que é viável a formulação de um embutido cárneo curado, à base de carne suína e que se enquadre na legislação vigente de produtos light; que a goma carragena é um bom substituto da gordura nas concentrações de 0,3 e 0,6\%; e que a substituição do sal comum ( $\mathrm{NaCl}$ ) por sal light (rico em $\mathrm{KCl}$ ) é viável desde que seja utilizada concentração de 0,25\% deste último.

KEETON, J.T. Fat Substitutes and fat modification in processing. Reciprocal Meat Conference Proceedings, Manhattan, v. 44, p. 79-91, 1991.

MURPHY, S.C. et al. Evaluation of surimi, fat and water content in a low/no added pork sausage formulation using response surface methodology. Meat Science, v. 66. p. 689-701, 2004.

PAPADIMA, S.N.; BLOUKAS, J.G. Effect of fat level and storage conditions on quality characteristics of traditional Grek sausages. Meat Science, v. 51, p. 103-113, 1999.

PEDROSA, L.F.C.; COZZOLINO, S.M.F. composição centesimal e de minerais de mariscos crus e cozidos na cidade de Natal/RN. Ciência e Tecnologia de Alimentos, v. 21, n. 2, p. 154-157, 2001.

STONE, H.; SIDEL, J.L. Sensory evaluation praticez. 2. ed. Academic Press, 1993. 337p.

SWANSON K.M.J., PETRAN, R.L.; HANLIN, J.H. Culture methods for enumeration of microorganisms. In: DOWNES, F.P.; ITO, K. Compendium of methods for the microbiological examination of foods. $4^{\text {th }}$ ed. American Public Health Association (APHA). Washington, 2001, 676 p., cap. 6, p. 53-62.

TARLADGIS, B. G. et al. Distillation Method for the Quantitative Determination of Malonaldehyde in Rancit Foods. Journal of American Oil Chemistry Society, v. 37, p. 44-48, 1960.

ZANARDI, E. et al. Lipid and colour stability of Mylano-type sausages: effect of packing conditions. Meat Science, v. 61, p. 7-14, 2002. 